\title{
Petro physical analysis of among hydrocarbon field fluid and lithofaciesusing Well Log Data
}

\author{
Sonny Inichinbia ${ }^{1}$, Peter O. Sule ${ }^{2}$, Aminu L. Ahmed ${ }^{2}$, HaliduHamza ${ }^{2}$ and \\ Kolawole M. Lawal ${ }^{2}$ \\ ${ }^{I}$ Department of Physics, Ahmadu Bello University, Zaria, Nigeria \\ ${ }^{2}$ Department of Geology, Ahmadu Bello University, Zaria
}

\begin{abstract}
Petrophysical imaging of two reservoirs of Amangi hydrocarbon field of the Niger Delta of Nigeria was conducted based on crossplot analysis using AVO information from well log data of five appraisal wells in the field. The field consists of series of reservoirs stacked in channelized shoreface sands encased in shales. Two reservoirs $\mathrm{H} 100 \mathrm{O}$ and $\mathrm{H} 400 \mathrm{O}$ which constituted the first phase of development of this field formed the pivot of this study. Firstly, we extractedpetrophysical parameters such as $P$ and $S$ impedances, Lamé's parameters, etc. Secondly, appropriate pairs of rock attributes and properties were crossplotted so that common lithologies and fluid types cluster together for quick identification and interpretation.

Furthermore, crossplotsof AVO intercept versus gradient and reflectivity versus incidence angle were analyzed to determine the class of AVO anomaly. The lithology and fluid contents of both reservoirs were adequately discriminated by the crossplot analyses of the rock properties and attributes. However, whereas there was a marked separation of litho-fluids in the density domain, the acoustic impedance domain proved incapable of separating the litho-fluids of these horizons. The reservoirs' sands were found to be "hard" sands as a result of mixed lithologies (heterolithics) exhibiting Class II AVO anomaly.
\end{abstract}

Keywords: Amplitude Variation with Offset (AVO), Lambda-Rho, Mu-Rho, Petrophysical, P-impedance, Simpedance,

\section{Introduction}

One critical part of seismic reservoir characterization is the careful analysis and understanding of petrophysical properties from well logs and core data. Hence, seismic petrophysics was performed on some wells in Amangi Field as an aid to improve calibration of seismic attributes to reservoir properties, well-toseismic ties and interpret $\mathrm{P}$ and $\mathrm{S}$ impedance inversions for gas saturation, porosity and net-to-gross. This will reduce risk and increase asset value as a rich gas condensate field.

The field was discovered by well-002 which was drilled in 1992 and was initially covered in that same year by a $2 \mathrm{D}$ seismic survey that was reprocessed in 2005. Imaging of the crest of the structure remained very poor. Also, uncertainties about the lateral extent of the reservoirs, pinchout, distribution of reservoir properties (such as porosity, net pay thickness, fluid type and fluid saturation, etc), and fault positions along the reservoirs are some challenges that are not yet fully understood. There are also exploration challenges in the data set of the field, such as the discrimination of hydrocarbon bearing sands from shales and more importantly, the separation of gas sands from brine saturated sandstones. So, a new anisotropic 3D seismic data was acquired between 2008 and 2010 and processed in 2011. Some more appraisal wells have also been drilled in this area and logging activities carried out in them.Petrophysical analysis will help resolve and also give some insight to further analysis that could resolve these problems.

Subsurface heterogeneity delineation is a key factor in reliable reservoir characterization. These heterogeneities occur at various scales and can include variations in lithology, pore fluids, clay content, porosity, pressure, and temperature [1]. Amplitude is a surface related property whereas variation in amplitude can be a reservoir property. This is sometimes the reason for failure of direct hydrocarbon indicators (DHI) driven exploration campaigns. Mere amplitude contrast may be ambiguous and may be out of several other factors other than hydrocarbon.Prestack seismic inversion which is related to variation of amplitude with offset or angle can generate attributes which are related to bulk and shear moduli whose derivatives in some cases can be excellent gas zone indicators [2].

Crossplots are visual representations of the relationship between two or more variables, and they are used to visually identify or detect anomalies which could be interpreted as the presence of hydrocarbon or other fluids and lithologies.Crossplotting is widely used in AVO analysis, becauseit facilitates the simultaneous and meaningful evaluation oftwo or more attributes. Generally, common lithology units and fluidtypes cluster together in AVO crossplot space, allowingfor a quick and easy identification of background lithology trends and anomalous off trend aggregations that could be associated withthe presence of hydrocarbons.Initially, AVO crossplotting typically used the interceptand gradient. 
However, crossplots of elastic parameters such as Lambda-Rho $(\lambda \rho)$ and Mu-Rho( $\mu \rho)$ has been used toimprove the petrophysical discrimination of rock propertiesas seen in[3].Other attributes have also been used as AVO anomaly indicators $[4,5,6]$. Crossplotting appropriatepairs of attributes so that common lithologies and fluidtypes generally cluster together allows for straightforwardinterpretation. The off-trend aggregations can then be moreelaborately evaluated as potential hydrocarbon indicators.This is the essence of successful AVO crossplot analysis andinterpretation, all of which is based on the premise that datathat are anomalous statistically are interesting geologically.

According to[7], in well log data we can generallyidentify two types of fields. Seismicfields represent sediment properties thataffect seismic wave propagation in thesubsurface. Nonseismic fields are othersediment properties that are of interestfor seismic reservoir description but donot affect directly the seismic wave propagation.In this case, the seismic fields are the welllog compressionaland shear velocities and the density $\log$, and thenonseismic fields are welllog estimates of porosity, water saturation $\left(\mathrm{S}_{\mathrm{w}}\right)$, net-to-gross $(\mathrm{N} / \mathrm{G})$ and clay content $\left(\mathrm{V}_{\mathrm{cl}}\right)$

Rock physics analysis is the key to relating the seismic properties to reservoir properties and high quality seismic reservoir characterization requires well log data that are consistent between formations and wells over the entire vertical interval of interest and represent the true undisturbed rock properties. The well data used in this study were quality controlled for these criteria, and corrections were applied where necessary by the petrophysicist. Through extensive crossplot analysis of various rock properties and attributes we tried to discriminate the lithology and fluid properties of the two reservoirs under consideration.

\section{The study area}

Amangi Field is located $70 \mathrm{~km}$ northwest of Port Harcourt within licence OML 21 of the Niger Delta of southern Nigeria as shown in Fig. 1. This field measuring $12 \mathrm{~km} \times 5 \mathrm{~km}$ is still a prospect and has not yet been fully appraised. The Niger Delta lies between latitudes $4^{\circ} \mathrm{N}$ and $6^{\circ} \mathrm{N}$ and longitudes $3^{\circ} \mathrm{E}$ and $9^{\circ} \mathrm{E}$.

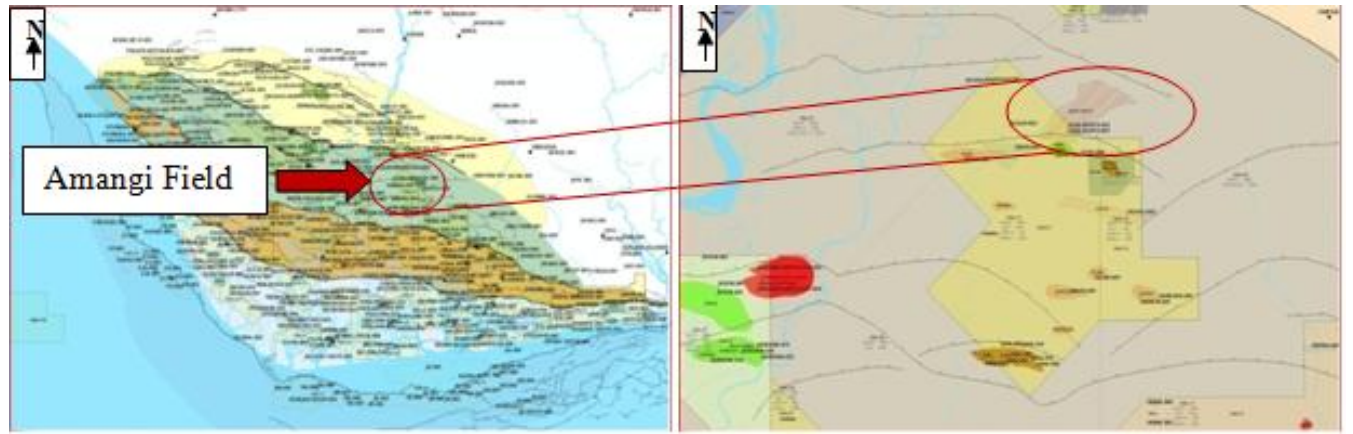

Figure 1. Map of the Niger Delta showing the study area. The encircled portion is the location of Amangi Field. (Source: Shell Petroleum Development Company of Nigeria Ltd.).

The structure of Amangi field is a complex collapsed crest, rollover anticline, predominantly shore face and channel deposits with distinctive coarsening upward characteristics. Hydrocarbons in the field are found between 7,300 ftss and 12,600 ftss in a predominantly deltaic sequence consisting of alternating sands, silts and shale layers [8].The Niger Delta is a coarsening upward regressive sequence of Tertiary clastic sediments which is divided into three lithostratigraphic units representing prograding depositional facies. These units are distinguished mostly on the basis of sand-shale ratios as follows: the Akata Formation at the base of the delta, Agbada Formation overlying the AkataFormation and the Benin Formation overlying the Agbada Formation.Knowledge and understanding of the geology of the Niger Delta is gotten from the detailed works of $[9,10,11,13,14,15]$.

\section{Well log data}

Six wells have penetrated the H1000 reservoir in the Amangi Field and only three wells have penetrated the $\mathrm{H} 4000$ reservoir. All the wells have at least a basic log suite to support a basic petrophysical evaluation. Two gas bearing sandstone reservoirs $\mathrm{H} 1000$ and $\mathrm{H} 4000$ have been encountered in five wells in the Tertiary Agbada Formation of Amangi field of the Nigerian Delta. Extensive logging dataset were acquired and displayed in Table 1. The location of some of the wells in the study area is shown in Fig. 2 and the well log data availability summary for Amangi Field is presented in Table 1. 


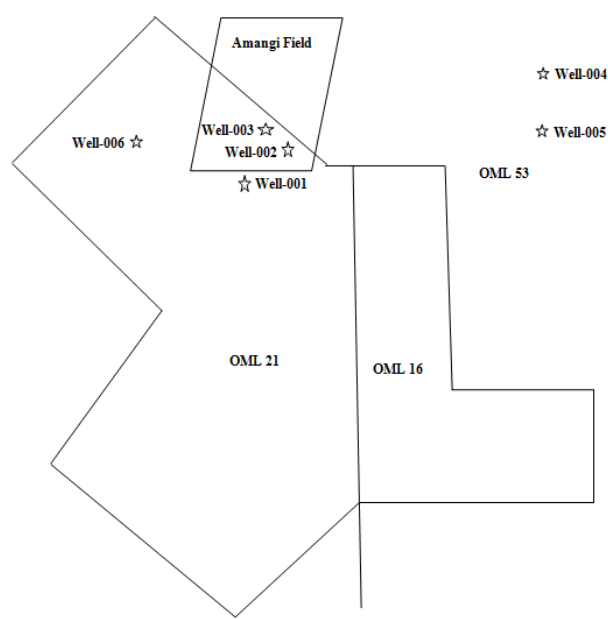

Figure 2.OML map of the study area showing the location of the wells in this study area. Four out of a total of six wells are located in OML 21 whereas the rest two wells are sited in OML 53.

Table 1. Some wells in Amangi Field showing suite of logs in each well. Only Well-002 has a complete suite of good quality logs in the area, needed for this work.

\begin{tabular}{|l|l|l|l|l|l|l|l|l|}
\hline Well & $\begin{array}{l}\text { GR } \\
(\mathbf{A P I})\end{array}$ & $\begin{array}{l}\text { CALL. } \\
(\text { inches })\end{array}$ & $\begin{array}{l}\text { RESIS. } \\
(\mathbf{\Omega} \mathbf{m})\end{array}$ & $\begin{array}{l}\text { DEN. } \\
\left(\mathrm{g} / \mathrm{cm}^{\mathbf{3}}\right)\end{array}$ & $\begin{array}{l}\text { SONIC } \\
(\mu \mathrm{fs} / \mathrm{ft})\end{array}$ & $\begin{array}{l}\text { PRES. } \\
(\mathbf{p s i})\end{array}$ & FIT & Checkshot(ms) \\
\hline $\begin{array}{l}\text { Well- } \\
\mathbf{0 0 1}\end{array}$ & YES & YES & YES & NO & YES & NO & NO & YES \\
\hline $\begin{array}{l}\text { Well- } \\
\mathbf{0 0 2}\end{array}$ & YES & YES & YES & YES & YES & YES & YES & YES \\
\hline $\begin{array}{l}\text { Well- } \\
\mathbf{0 0 3}\end{array}$ & YES & YES & YES & YES & YES & YES & NO & NO \\
\hline $\begin{array}{l}\text { Well- } \\
\mathbf{0 0 4}\end{array}$ & YES & YES & YES & YES & YES & NO & NO & NO \\
\hline $\begin{array}{l}\text { Well- } \\
\mathbf{0 0 5}\end{array}$ & YES & YES & YES & YES & YES & NO & NO & NO \\
\hline
\end{tabular}

From the table well-002 was identified with a complete suite of good quality logs that sampled all or most of the logging types and lithologies and some of its logs are further displayed in Fig. 3. The sonic data were calibrated with the checkshot data. The lithology classification is shown in track 7 in which sand is yellow and shale is green. Compressional and shear sonic logs in (tracks 3 and 4) and density log is intrack 14. Resistivity and porosity curves are in tracks 6 and 11, respectively. The gamma ray, calliper, neutron, neutrondensity, $\mathrm{V}_{\mathrm{p}}$, and $\mathrm{V}_{\mathrm{s}}$ curves are in tracks $2,5,8,9,10,12$ and 13 respectively. The measured depth and the two way travel time are recorded in track 1 . The numbering of the tracks is done from left to right. The calliper log shows stable borehole conditions.

In sand dominant sections, borehole quality is relatively good. The hydrocarbon sand sections have distinct log motifs and properties as compared to the underlying and overlying shale. The thick gas reservoirs are characterized by higher resistivities and neutron-density crossover. The reservoir sands are recognized by their very low gamma ray, low density, low sonic, very high resistivity, and high neutron-porosity. The sands are siliciclastic, finegrained, soft to moderately hard, showing fining upward motifs and sometimes blocky, coarseningupward motifs. Sandstone layers are separated by shale. Sidewall samples, checkshot and vertical seismic profiling (VSP) data were available for this study. 


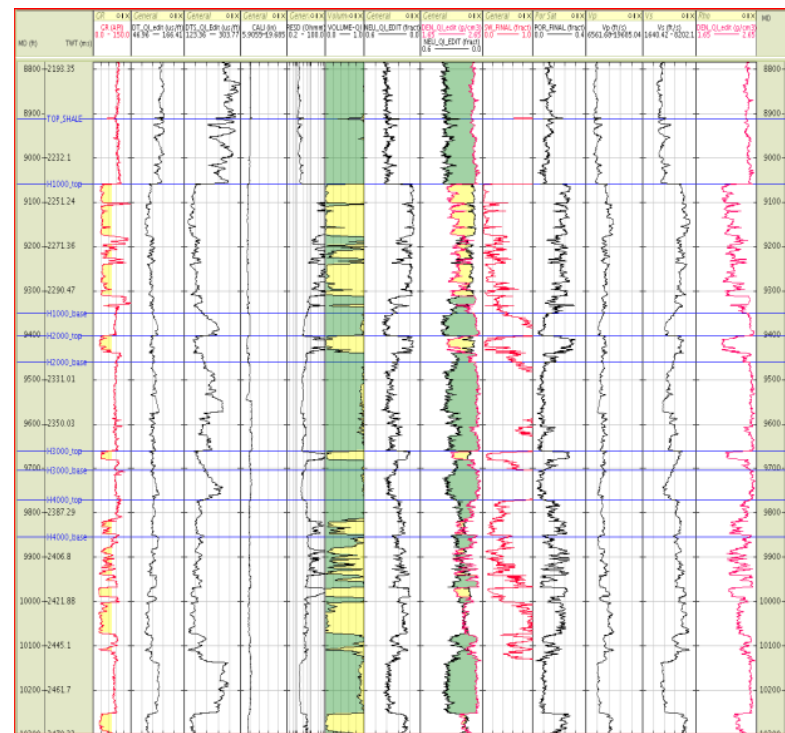

Figure 3.Typical log signatures of shales/sands section in the area of study as seen in well-002. Gamma ray, sonic, caliper, resistivity, volume shale, neutron, porosity, water saturation, $V_{p}, V_{s}$ and density $\operatorname{logs}$ from well-002 used in this study. The thick gas reservoirs are characterized by higher resistivities and neutron-density crossover.

\section{Methodology}

The method employed followed from the works of $[3,16,2]$. It involved simple analysis of available well information(logs, sidewall samples and geology) from the well where data and interpretation are most complete and reliable, to obtain lithology and pore fluid definition. Basic rockphysics relations such as velocityporosity, impedances, Lamé'sparameters and $\mathrm{V}_{\mathrm{p}} / \mathrm{V}_{\mathrm{s}}$ among others weredefined for the lithofacies. This is followed by computations of the litho-fluid dependent seismic attributes of interest fromAVO analysisand inversion. We then initiated the litho-fluid definition with exploratory crossplots between different logs and attributes looking for cluster separation.

\section{Petrophysical analysis}

Before creating seismic attributes for the whole 3D seismic volume as gas reservoir indicator we ensured whether its sensitivity was significant to resolve the gas zones at the target locations from the well logs.This was because sensitivity of seismic attributes androck properties responding to pore fluid and lithology contrast are two important issues for defining a reservoir.Lithology contrast and sensitivity of reservoir rocks with respect to pore fluid is a function of porosity, fluid type and rock composition such as shale volume in sandstone. The sensitivity was determined by the variation of basic rock properties: velocities and density. Other rock properties such as impedances and elastic moduli were derived from these basic rock properties. Individual rock property responds differently or has different sensitivity to a given lithology or fluid contrast. Fundamentally, if the gas zones are separable in the well derived attribute then only it can be expected to work in seismic volume.

Fig.4 is the crossplot of P-wave velocity $\left(\mathrm{V}_{\mathrm{p}}\right)$ and $\mathrm{S}$-wave velocity $\left(\mathrm{V}_{\mathrm{s}}\right)$, from the gas reservoir intervals as a function of volume of shale $\left(\mathrm{V}_{\mathrm{sh}}\right)$ and gamma ray $(\mathrm{GR})$ and shows that the lithologies and fluids can be separated in the $V_{p}$ versus $V_{s}$ domain. These logs were derived from the recorded full wave form sonic logs. Three rock types were identified, namely, shale, brine sand and gas sand. There is good separation between brine sand and gas sand as predicted by [17]. But there is also a separation between brine sand and shale, which is contrary to their prediction that they lie on the same mudrock line. This means that weak fluid factor reflections will occur at brine sand and shale boundaries as well as at brine sand and gas sand boundaries. Strong fluid factor reflections will occur at shale and gas sand boundaries because of the large separation between the shale and gas sand clusters [18].

The gas sands have higher $\mathrm{V}_{\mathrm{p}}$ values $3,078 \mathrm{~m} / \mathrm{s}-3,261 \mathrm{~m} / \mathrm{s}(10,100 \mathrm{ft} / \mathrm{s}-10,700 \mathrm{ft} / \mathrm{s})$ and $\mathrm{V}_{\mathrm{s}}$ values $1,828 \mathrm{~m} / \mathrm{s}-2,133 \mathrm{~m} / \mathrm{s}(6000 \mathrm{ft} / \mathrm{s}-7000 \mathrm{ft} / \mathrm{s})$ than the shale $2,590 \mathrm{~m} / \mathrm{s}-3,048 \mathrm{~m} / \mathrm{s}(8500 \mathrm{ft} / \mathrm{s}-10,000 \mathrm{ft} / \mathrm{s})$. But lower $\mathrm{V}_{\mathrm{p}}$ values than the underlying brine sands $3,353 \mathrm{~m} / \mathrm{s}-3,810 \mathrm{~m} / \mathrm{s}(11,000 \mathrm{ft} / \mathrm{s}-12,500 \mathrm{ft} / \mathrm{s})$ and the $\mathrm{V}_{\mathrm{s}}$ values of the brine sand is higher than that of the gas sands. High porosity sands fall at the low velocity ends of both the gas sand and brine sand clusters whereas low porosity sands fall at the high velocity ends. Cut-off is $<0.35$ for sand and $>0.35$ for shale. 


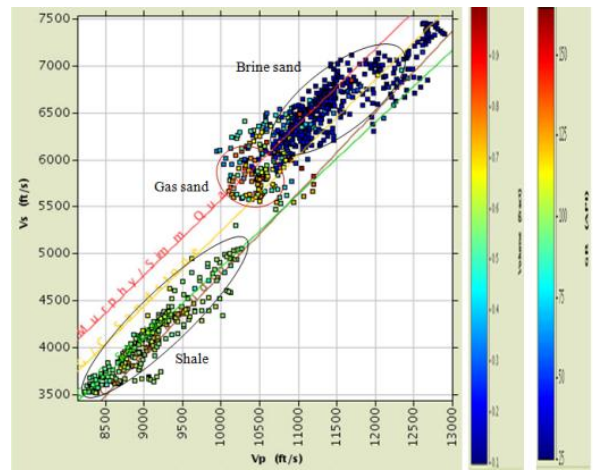

Figure 4. $V_{p}$ versus $V_{s}$ crossplotcolour coded to gamma ray (GR) and volume fraction of shale $\left(V_{s h}\right)$ showing separation of lithologies from their velocities. The sands display higher compressional and shear velocities.

We then investigated the P-wave velocity versus porosity and the P-wave velocity versus density relationships by crossplotting these properties colour coded to gamma ray in Fig.5, to determine the velocityporosity and velocity-density content dependence for the two reservoir zones. $\mathrm{V}_{\mathrm{p}^{-}} \mathrm{V}_{\mathrm{s}}$ relations of typical reservoir rocks are known to be well correlated, as well as dependent on lithology: sandstones tend to have linear $\mathrm{V}_{\mathrm{p}}-\mathrm{V}_{\mathrm{s}}$ relations. Low porosity points indicate shales in the velocity versus porosity crossplot. We can see good correlation between velocity and gamma ray, and velocity and porosity showing clear trends that indicated that $\mathrm{V}_{\mathrm{p}}$ decrease with increasing porosity.

The sands range from grey to dark grey; very fine lower to very fine upper; very silty; very well sorted; clayey; slightly calcareous; loosely consolidated sands. Moreover, porosity correlates with gamma ray, the smaller the gamma ray values the larger porosity. The gamma ray response is a good indicator of lithology and reservoir quality in the field. Thus, low gamma ray values indicatelow clay content and are associated with sandstones. On the contrary high values of gamma ray indicate high clay content and are related to shale or siltstones.

Yellow colour corresponds to the sands or low shale content while green/red colour indicates high shale content. The level of scattering of these rocks can likely be related to the clay content, which affects not only the stiffness of the rock but also the pore geometry and the aspect ratio [19].In this model, velocity is affected by porosity and clay content, porosity being the main factor. These two reservoirs are associated with rocks with porosities that are about $21 \%$. They are composed of clean sandstones with intercalations of shale. For the whole reservoir zones, P-wave velocity is a good discriminator of lithology. Similarly, the compressional sonic logs could be used as a reliable discriminator of lithology or fluid content.

Based on the crossplots from the wells, we found that the P-impedance, velocity, porosity, and shale volumes do not show good correlation over the study area. Density shows a good correlation with lithology (porosity and volume of shale). In addition, density correlates more with the impedance layering. From [20], seismic velocities do not have to increase with bulk density. Because the normal incidence reflection coefficient for a shale-sand interface is normally weak and the difference between $V_{P}$ for shale and sand is also small, it is hard to see any difference in the effective medium velocity with changes of net-to-gross (N/G). By weak contrast, we mean that the $V_{P}$ for sand and shale are very similar; as a result, the phase change attributed to propagation in sand and shale is approximately the same [21]. The frequency content of the reflection response is also very similar.

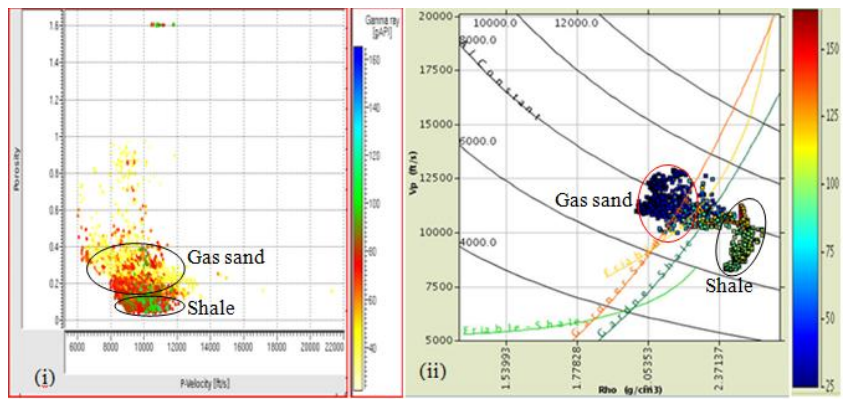

Figure 5.Crossplots of (i) $P$-wave velocity versus porosity (ii)density versus $P$-wave velocity colour coded to gamma ray values showing lithofacies.Shales (green colour) and sands (blue and yellow colours respectively) cluster separately, with shales exhibiting larger densities. $V_{\mathrm{p}}$ is the compressional velocity in $\mathrm{ft} / \mathrm{s}$ and $\mathrm{Rho}(\rho)$ is the bulk density in $\mathrm{g} / \mathrm{cm}^{3}$. 
To determine layer properties rather than interface properties, we inverted the seismic amplitudes into acoustic impedance. From [19] model based inversion, which is a robust inversion method that accounts for the well data and seismic interpretation, provided significant information of the spatial distribution of these properties in terms of changes in acoustic impedance. Seismically, the top of the reservoir units represent low contrasts in velocity and acoustic impedance that could not facilitate lithology prediction from seismic data. These units, which can be grouped and considered a single unit for seismic purposes, are embedded into thick layers of shale of generally comparable velocity and acoustic impedance. The lateral amplitude changes of these reflections may be related to porosity and lithologic changes seen in the wells.

The interpretation of the well log displayed in the P-impedance versus S-impedance crossplot is key to understanding the behaviour of sands with different fluids. Fig.6 is a crossplot of P-impedance against Simpedance colour coded to gamma ray values. The rock types separate into linear trends as in Figure 1and there isslightly less scatter of the points. The gas sand package is displaced toward the lower left and the brine sands are displaced toward the upper right because the reservoir sands have lower densities than the shales. We notice "hard" sandstones (P-impedance in excess of about 22,000 g/cm $3 \mathrm{ct}^{3} / \mathrm{s}$ and $\mathrm{V}_{\mathrm{s}}$ above $13,000 \mathrm{~g} / \mathrm{cm}^{3} \mathrm{ft} / \mathrm{s}$ ).

There are also exploration challenges in the data set, such as the discrimination of hydrocarbon bearing sands from shales and, more importantly, separation of gas sands from brine saturated sandstones. Thus, we have lithology-lithology ambiguities as sand (low gamma ray values) and shale (high gamma ray values) have the same or overlapping acoustic impedance which could cause no reflectivity on a near offset seismic section. Thus, the sandstones are clearly anomalous; they should therefore be identifiable from a simultaneous inversion to $\mathrm{P}$ and $\mathrm{S}$ impedance. This crossplot shows major petrofacies and end member parallel trends in agreement with shale $(\mathrm{N} / \mathrm{G}=0)$ and gas sand $(\mathrm{N} / \mathrm{G}=1) \log$ impedance data.

Thus, to marry the log model petrofacies classification to the 3D seismic inversion, it is imperative to demonstrate that the major petrophysical groups can be distinguished in the P-impedance versus S-impedance space in the target zones. Clearly each petrofacies finds its own place in the P-impedance versus S-impedance space in these main reservoir zones. Because channel sand sections existed in this reservoir, they are plotted along the hydrocarbon sand trend with $\mathrm{V}_{\text {sand }}=1$.
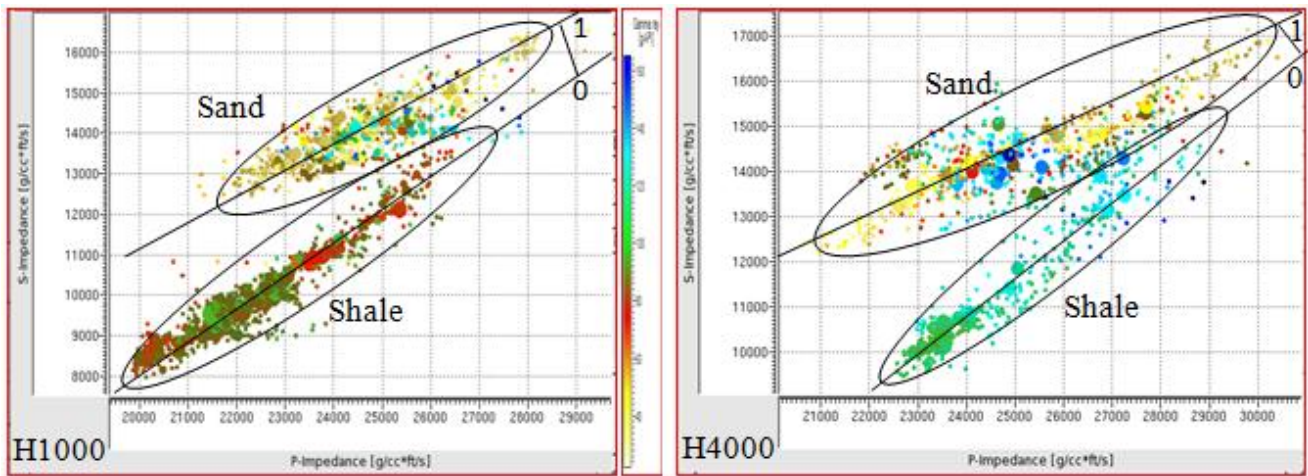

Figure 6. P-impedance versus $\mathrm{S}$-impedance crossplot showing major petrofacies inH1000 and $\mathrm{H4000}$ respectively, colour coded to gamma ray. The plots indicate separate trends for sand and shale, but $P$. impedance level alone cannot discriminate the lithologies but $\mathrm{S}$-impedance does. The sands are anomalous and could easily be confused with shales which have similar P-impedance values.

To interpret the lithology, we strongly depended on data integration adding the information from wells and a prior knowledge on the geology of the field.Brine sands show much higher P-impedances than do gas sands. There is also a difficulty separating the brine sands and gas sands from the shales since they have some overlapping impedance values. Thus, it is difficult to delineate hydrocarbon reservoirs directly on the separate inverted P-impedanceand S-impedancesections. Ambiguities in lithologic and fluid identification based only on the acoustic impedance can often be effectively removed by adding information about $\mathrm{V}_{\mathrm{p}} / \mathrm{V}_{\mathrm{s}}$ related attributes at nonnormal incidence $[22,23,24,25]$.

From [26], the ratio $\mathrm{V}_{\mathrm{P}} / \mathrm{V}_{\mathrm{S}}$ contains information about the lithology of the rocks. It also provides vital details on the fluid contents and is related to the porosity of the rocks. However, gas sands are known to have anomalous low $\mathrm{V}_{\mathrm{p}} / \mathrm{V}_{\mathrm{s}}$ ratios. Thus, if we can relate the inverted P-impedance $\left(\mathrm{I}_{\mathrm{p}}\right)$ and $\mathrm{S}$-impedance $\left(\mathrm{I}_{\mathrm{s}}\right)$ sections to $\mathrm{V}_{\mathrm{p}} / \mathrm{V}_{\mathrm{s}}\left(\right.$ or $\left.\mathrm{I}_{\mathrm{p}} / \mathrm{I}_{\mathrm{s}}\right)$ and to pore fluid content, we have a first step to separate the lithologic and pore fluid effects. Subsequent mapping to one more parameter, the water filled porosity, which is estimated as the sum of all the water components in the pore space (the volume fractions of movable water, bound water, and water trapped in unconnected pores), further improves discrimination between pore fluids in the sandstone reservoirs. The presence and effects of thin and mixed lithologies are still apparent in the crossplot, with variation in clay content dispersing the shale and claystone clusters, while hydrocarbon saturation silt/clay content affect the 
brine sand and gas sand clusters. Thus, this environment is more transitional, resulting in some sand/shale cluster overlap.Note that the acoustic impedance of the gas sand and the encasing shale are about equal, so the sandstones would easily be confused with the shales had not the shear information been available [27,28].

In Fig.7,wecreated a crossplot of acoustic impedance and $\mathrm{V}_{\mathrm{p}} / \mathrm{V}_{\mathrm{s}}$ data from the target zones based on the well log data. This crossplot is compared to rock physics templates for various net-to-gross ratios. The templates are made following the methodology similar to the one by [29]. The characteristic shale was picked from the sealing shales above and below the reservoirs. This may be somewhat erroneous because the sealing shale is not necessarily equivalent to the interbedded shale within the reservoirs. However, shales always have higher $\mathrm{V}_{\mathrm{p}} / \mathrm{V}_{\mathrm{s}}$ ratios than reservoir sands. As a result, when the sealing shales and reservoir sands have similar $\mathrm{P}$ impedances, their S-impedances are different as shown in Fig.6.

From AVO analysis we can also distinguish the gas sand from brine sand and shale with the $\mathrm{V}_{\mathrm{p}} / \mathrm{V}_{\mathrm{s}}$ versus P-impedance crossplot. Gas saturated sands in well-002 show some amount of increase in P-impedance. But the P-impedance space alone could not adequately delineate the rock types because of a reasonably large degree of overlap in the P-impedance values of the rock units. However, the shale dominated section and the sand dominated section are clearly identified and separated on the plot in the $\mathrm{V}_{\mathrm{p}} / \mathrm{V}_{\mathrm{s}}$ domain. Because shear waves are insensitive to fluid changes, while compressional waves are, changes in fluid type and saturation will result in $\mathrm{V}_{\mathrm{p}} / \mathrm{V}_{\mathrm{s}}$ changes. Thus, $\mathrm{V}_{\mathrm{p}} / \mathrm{V}_{\mathrm{s}}$ or impedance ratios can be used successfully for direct hydrocarbon detection, especially with AVO techniques. Therefore, crossplotting the $\mathrm{V}_{\mathrm{p}} / \mathrm{V}_{\mathrm{s}}$ ratio against P-impedance shows a distinct separation in $\mathrm{V}_{\mathrm{p}} / \mathrm{V}_{\mathrm{s}}$ between the sand and shale. The variation in $\mathrm{V}_{\mathrm{p}} / \mathrm{V}_{\mathrm{s}}$ at the sand shale interface gives rise to a change in reflection amplitude with offset at the lithologic boundary.
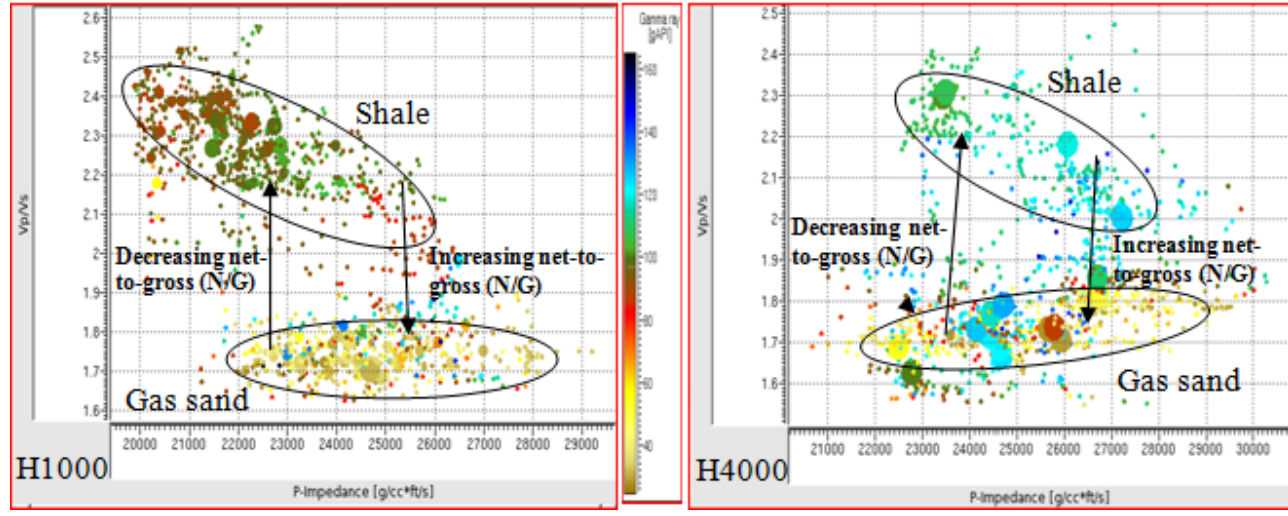

Figure 7.P-impedance versus $\mathrm{V}_{\mathrm{p}} / \mathrm{V}_{\mathrm{s}}$ Crossplot for different facies and fluids in the area of study. The sands span $V_{p} / V_{s}$ ratios from 1.5-2. Most of the gas sands have $V_{p} / V_{s}$ of 1.6-1.7 representative for $N / G$ values of

0.9. Hence, very little shale intercalation will cause a significant increase in $V_{p} / V_{s}$ ratios compared to homogeneous, clean sands $(\mathrm{N} / \mathrm{G}=1)$.

So, the $\mathrm{V}_{\mathrm{p}} / \mathrm{V}_{\mathrm{s}}$ space proved adequate in separating the different rock types. We could envisage the various models for the N/G of 1, 0.9, 0.8, 0.7, 0.6 and 0.5. For each of these N/G values we could envisage varying gas saturation within the sand layers. It is interesting to note how the decrease in N/G will cause a drastic increase of the $\mathrm{V}_{\mathrm{p}} / \mathrm{V}_{\mathrm{s}}$ ratio, regardless of porosity, even for high gas saturation in the sands [29]. Note that the hydrocarbon sands span $\mathrm{V}_{\mathrm{p}} / \mathrm{V}_{\mathrm{s}}$ ratio from $1.65-1.80$, indicating some intercalation of shale within the reservoirs. The $\mathrm{V}_{\mathrm{p}} / \mathrm{V}_{\mathrm{s}}$ cutoff here is 1.8 .

One useful parameter for quantification of the heterogeneity of sands is theN/G, which is the fraction of clean, permeable sand to the complete reservoir including reservoir sands and intercalating impermeable shales. However, N/G is a scale dependent parameter. A reservoir zone can have high N/G at well log scale, but low $\mathrm{N} / \mathrm{G}$ at seismic scale [30]. Thus, decrease in the $\mathrm{N} / \mathrm{G}$ causes a drastic increase of $\mathrm{V}_{\mathrm{p}} / \mathrm{V}_{\mathrm{s}}$ and very little shale intercalation will cause a significant increase in $\mathrm{V}_{\mathrm{p}} / \mathrm{V}_{\mathrm{s}}$ compared to homogeneous, clean sands $(\mathrm{N} / \mathrm{G}=1)$ with $100 \%$ gas. We used the reservoir sand together with some interval of the sealing shale in the crossplots, and we can clearly observe that the gas saturated sands span a wide range of $\mathrm{V}_{\mathrm{p}} / \mathrm{V}_{\mathrm{s}}$ ratios, even close to 1.90 , a value more typical of brine saturated sands. This observation is consistent with a patchy saturation behavior. The heterogeneities of the intercalating shales are causing a geologic control on the saturation pattern. Hydrocarbon sands have $\mathrm{V}_{\mathrm{p}} / \mathrm{V}_{\mathrm{s}}$ ratio ranging from 1.6 to 1.8 . Gas saturated sands are clearly separated from the shales. The plot is colour coded to gamma ray values.

It is interesting to note how the decrease in $N / G$ will cause a drastic increase of the $V_{p} / V_{s}$ ratio, regardless of porosity, even for high gas saturation in the sands. The effects of thin and mixed lithologies are still apparent in the crossplot, with variation in clay content dispersing the shale and claystone cluster, while hydrocarbon saturation silt/clay content affect the brine sand and gas sand clusters.Hence, we can produce rock 
physics templates of $\mathrm{AI}$ versus $\mathrm{V}_{\mathrm{p}} / \mathrm{V}_{\mathrm{s}}$ that can be used for simultaneous interpretation or classification of porosity, saturation and the N/G from well $\log$ data as well as elastic inversion results [29].

A common way to extract porosity from seismic data is to do acoustic impedance inversion. The objective is to predict well log properties such as porosity and lithology from seismic attributes like acoustic impedance, which bear a theoretical relationship to log properties under some ideal conditions. In this study, the acoustic impedance is considered the most important attribute to make quantitative predictions of reservoir properties in the field, such as porosity and lithology. The acoustic impedance derived from seismic inversion versus porosity derived from density log is crossplotted in Fig.8 to show the relationship between porosity and acoustic impedance.This shows three main trends: one for relatively low to high impedance and low porosity (shale), another for relatively high impedance and high porosity (clayey or shaly sand), and the third for high impedance and high porosity (sand).

Although there is a considerable scatter of the data points in the crossplots, we can infer an inverse relation between porosity and impedance given by the slope of a regression line. We estimated an average porosity of 0.21 , for the reservoir sandstones, and discriminated them from the shale and brine sand. Pimpedance drops drastically when sands have high porosities but increase slightly when the sands have low porosity. This is of course due to the relative contrast to the intercalating shale. The porosity value indicates good quality reservoirs.

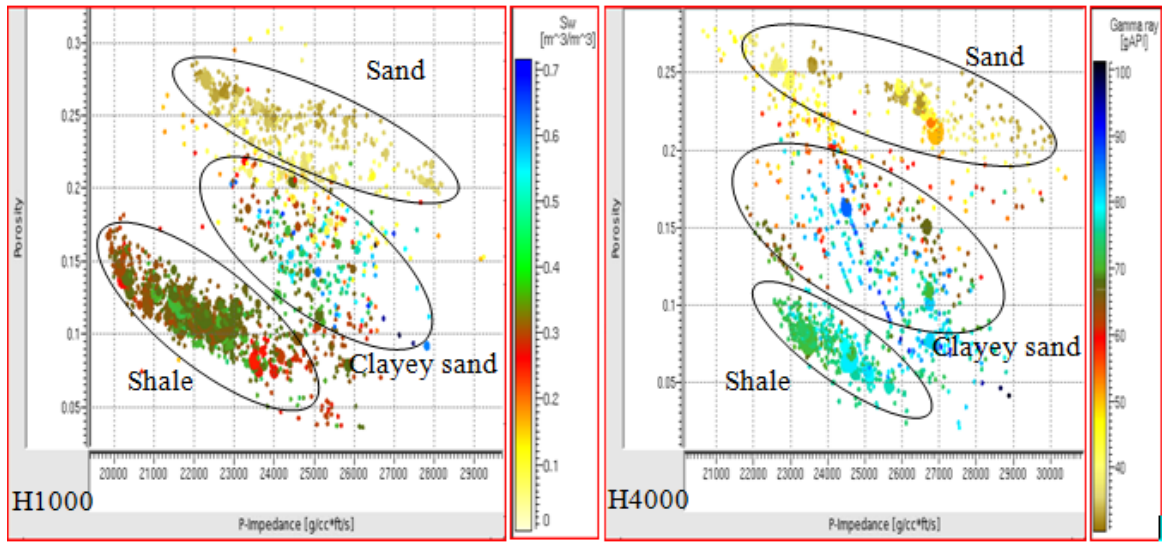

Figure 8. P-impedance versus porosity crossplot for $\mathrm{H1000}$ and $\mathrm{H4000}$, colour coded to gamma ray and water saturation. Porosity shows an inverse relation with P-impedance.

Using well log data we alsocrossplottedP-impedance versus gamma raycolour coded to resistivity and water saturationas shown in Fig.9. By this we establish a relationship between P-impedance and known rock properties within the specific target zones and within the frequency range of the inverted data set. The result shows that the lithologies could be discriminated in the gamma ray domain. In H1000 low gamma ray and high P-impedance is diagnostic of the hydrocarbon bearing sands of this zone. The sands are well separated from the shales on the gamma ray log.
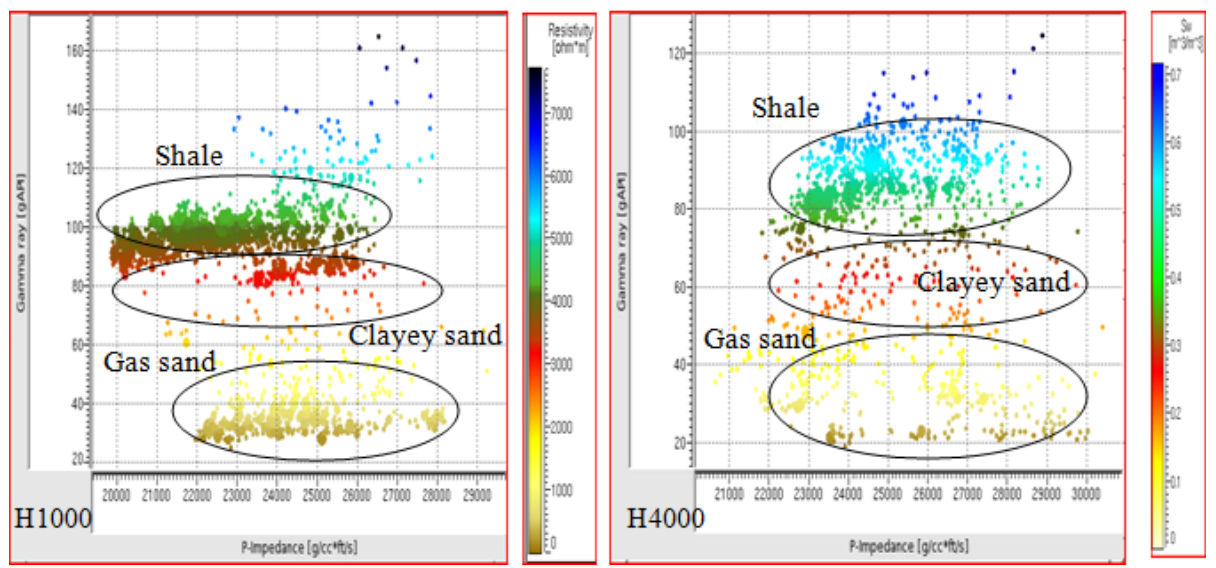

Figure 9. P-impadance and gamma ray crossplot for the to discriminate fluid and lithology - high Pimpedance, high resistivity and low gamma ray indicate hydrocarbon sand. 
From AVO inversion results at the well, we obtained Lamé'smoduli $(\mu)$ and $(\lambda)$ as demonstrated by [3].Combining them with density $\rho$; from the well $\log$ we obtain the parameter Mu-Rho ( $\mu \rho)$ and Lambda-Rho $(\lambda \rho)$, which are useful in distinguishing sand quality and fluid content. The subject of rigidity $(\mu \rho)$ and incompressibility $(\lambda \rho)$ helps in understanding the AVO response because they are fundamental concepts which could be considered independent and interpreted separately and in combination to provide additional information on the nature and content of the reservoir rocks and fluid. Since gas compresses easily, the presence of gas in sandstone (gas sand), causes a significant decrease in its incompressibility. Gas in sand does not affect its rigidity but sand has high rigidity, so the result is a significant AVO response which depends on the contrast between incompressibility and rigidity as observed in the $\lambda \rho-\mu \rho$ space of Fig.10. The sands have low water saturation values $(0.0-0.20)$ than the shales having higher water saturation $(0.22-0.50)$ which shows that the sediments are poorly consolidated.
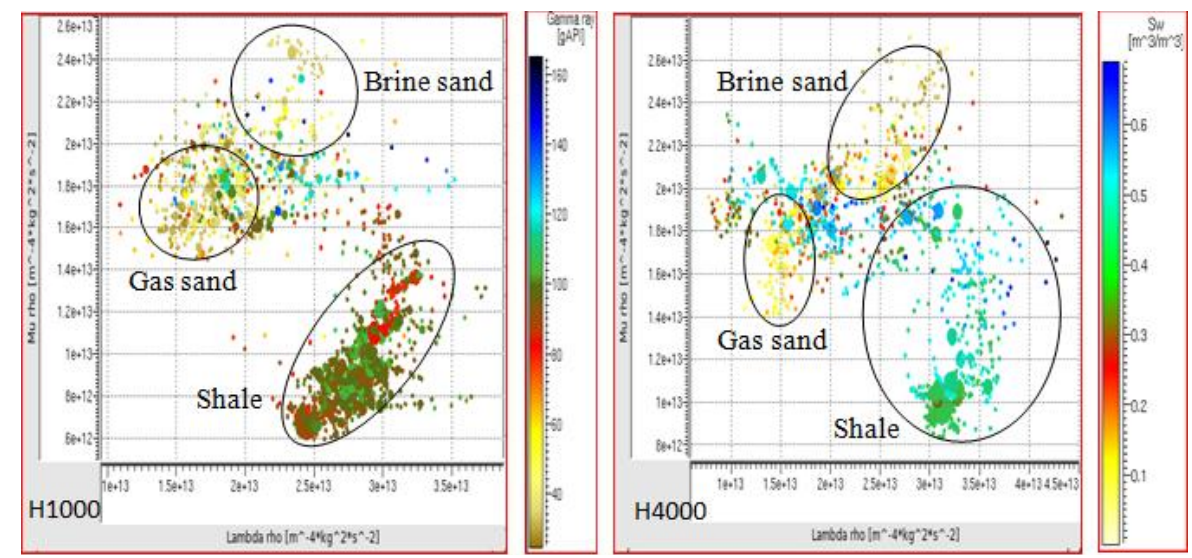

Figure 10.Lambda-Rho and Mu-Rho crossplot for $\mathrm{H} 1000$ and $\mathrm{H} 4000$, colour-coded to gamma ray and water saturation values. Log analysis shows that good discrimination of sandstone and shales is possible on the basis of rigidity where high rigidity discriminates sandstones from shales.

An effective fluid indicator can be found on a crossplot of $\lambda \rho$ versus $\mu \rho$. The intuitive interpretation of this is that $\lambda \rho$ and $\mu \rho$ are fundamentally more orthogonal than P-impedance $\left(\mathrm{I}_{\mathrm{p}}\right)$ and S-impedance $\left(\mathrm{I}_{\mathrm{s}}\right)$, stemming from the ambiguity in the $V_{p}$ and $V_{s}$ relationships that share the same value of rigidity $\mu$ [31]. The resolution of gas sand is enhanced in $\lambda \rho$ and $\mu \rho$ space due to a low $\lambda \rho$ value which gives a better contrast between sand and shale. The lowest $\lambda \rho$ (incompressibility $\mathrm{x}$ density) point has the best gas sand values along with $\mu \rho$ (rigidity $\mathrm{x}$ density) values higher than shales. $\lambda \rho$ versus $\mu \rho$ crossplot shows a significant advantage in isolating both lithologic properties and gas zones. The anomalous gas sands are in the upper left hand quadrant from the lowest $\mu \rho$ shales while other more competent pure lithologies (silts, cemented sands) plot in the opposite upper right quadrant relative to the shales.

The reason for the separation improvement in Fig.10 compared to Fig.6 is that the $\lambda \rho$ versus $\mu \rho$ axes are orthogonal with regard to Lamé'sparameters or moduli, unlike P-impedance versus S-impedance, thereby making the crossplot more discriminating. Identifying gas sand in $\lambda \rho$ and $\mu \rho$ space [3] has been proved successful. The degree of the orthogonality between any two lithologic units is the key for measuring the contrast. Improvement of contrast between gas sand and shale or other lithologic units is decided by their $\mu \rho$ values. Note that $\lambda \rho$ and $\mu \rho$ are directly derived from $\mathrm{P}$ and $\mathrm{S}$ impedances by:

$$
\lambda \rho=I_{p}^{2}-2 I_{s}^{2}
$$

$$
\mu \rho=I_{s}^{2}
$$

Crossplotting $\lambda \rho$ versus $\mu \rho$ has thus enabled fluid content and lithology to be discriminatedsince $\lambda \rho$ is sensitive to fluid and $\mu \rho$ is sensitive to lithology.This approach has been shown to be better hydrocarbon indicatorsthan the conventional method using $\mathrm{V}_{\mathrm{p}}-\mathrm{V}_{\mathrm{s}}$ orP- and $\mathrm{S}$ - impedances [3]. Thus, log analysis shows that good discrimination of sandstone and shales is possible on the basis of rigidity where high rigidity discriminates sandstones from shales.

In Fig.11, we observed that both $(\mu \rho) \mathrm{Mu}-\mathrm{Rho}$ and $\mathrm{V}_{\mathrm{p}} / \mathrm{V}_{\mathrm{s}}$ spaces could discriminate lithofluids in the area, as high $\mu \rho$ and low $V_{p} / V_{s}(1.8)$ indicate gas sand while higher $V_{p} / V_{s}(1.8-2.4)$ value indicate shale. Gamma ray values allow distinguishing lithological units interpreting sand from minimum values of gamma ray. The gamma ray response is a good indicator of lithology and reservoir quality in the field. 


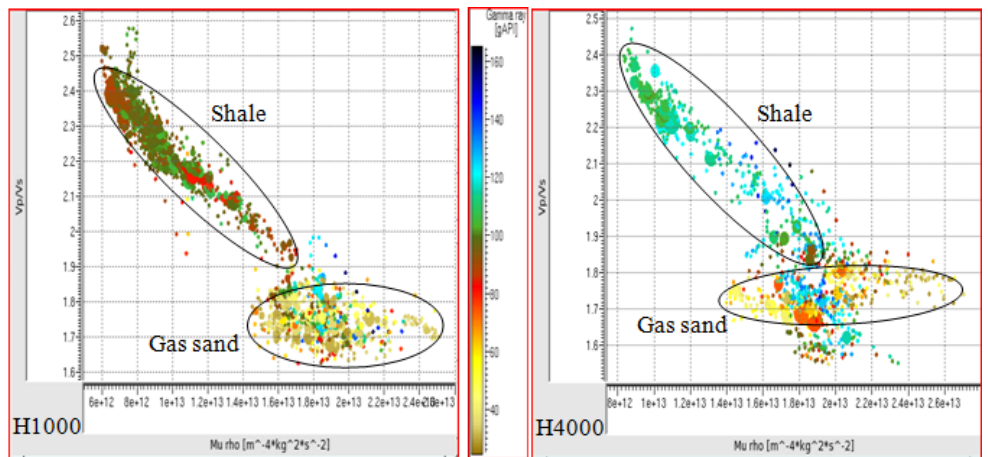

Figure 11. Mu-Rho versus $\mathrm{V}_{\mathrm{p}} / \mathrm{V}_{\mathrm{s}}$ crossplot for $\mathrm{H1000}$ and $\mathrm{H4000}$, colour coded with gamma ray values for quick lithology identification. The sands have high $M u-R h o$ values and $V_{p} / V_{s}$ value range of $1.6-1.8$ while the the shales have higher $V_{p} / V_{s}$ ratio range of 1.9 - 2.4 and lower Mu-Rho values.

Plots of reflectivity versus incidence angle $(\theta)$ from the well log data are shown in Figure12, for both reservoirs and we observed that H1000 sand shows Class IIp AVO response while H4000 shows a Class II response without phase reversal for the angle ranges displayed. Both H1000 and H4000 sands have higher velocity than the overlying shale so they are "hard" sands. This could was as a result of mixed lithologies (heterolithics). They have a negative reflection coefficient which magnitude increases with offset and changed sign (class IIp) as seen on the crossplot.

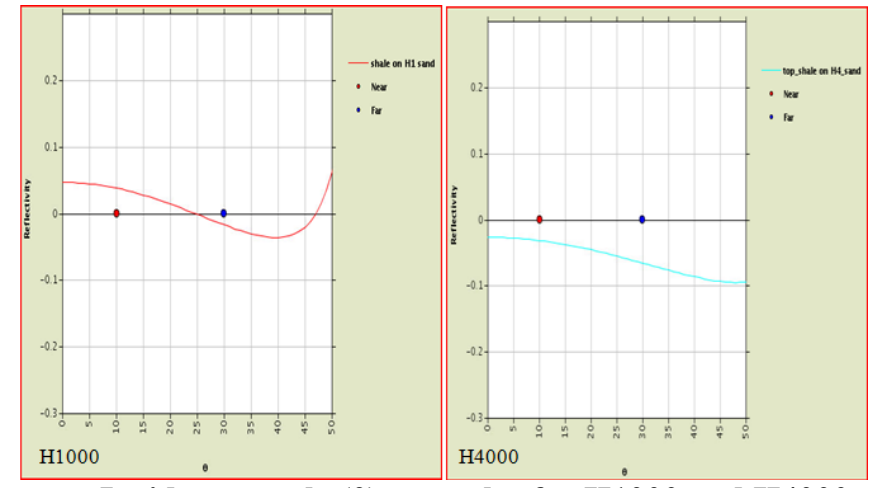

Figure 12. Reflectivity versus Incidence angle ( $\theta$ ) crossplot for $\mathrm{H1000}$ and $\mathrm{H4000}$, showing AVO response at the top of the reservoirs. Incident angles are calculated for each CMP using the RMS velocities selected for NMO corrections. These angles have been labelled on the abscissa of the graph. Normalized amplitudes for each trace are then plotted as a function of incident angle.

H1000 reservoir shows a class IIp anomaly while $\mathrm{H4000}$ reservoir shows a class II anomaly.

H4000 sand presents weak but negative intercept and negative gradient, hence, no polarity change whereas H1000 sand has a weak but positive intercept and a negative gradient causing a polarity change with offset. These anomalies represent sands saturated with hydrocarbons that have very weak zero offset contrast compared with the capping shale and are relatively deep. Thus,petrophysical analysis links reservoir properties such as porosity and gas saturation to elastic properties.

\section{Conclusion}

The petrophysicalanalysis revealed the difficulty in lithology discrimination from acoustic impedance. Full stack constrained sparse spike inversion cannot separate sand from shalebut rock trace AVO inversion using partial stacks could separate lithologies.Hence, by the combination of porosity against acoustic impedance from the transformation of the seismic reflectivities and density and porosityagainst compressional velocity, these analyses allowed separation of sand and shale facies.

Crossplot analysis is indeed a sophisticated interpretational tool for analyzing elastic rock properties/attribute in multidimensional space. Thus, helping us to understand how elastic rock properties are related and their sensitivity to various lithologies and fluid effects. Further analyses shall include P-impedance inversion of the anisotropic 3D seismic data to other rock properties and attributes to determine the N/G, Lambda-Mu-Rho, porosity etc, constraining the seismic with the well $\log$ data.The results from these analyses would demonstratein subsequent papers how this petrophysical analysishas helped improve well-to-seismic ties, calibration of seismic attributes to reservoir properties and interpretation of the 3D seismic data especially P-impedance and S-impedance inversions for gas saturation, net- 
to-gross and porosity in Amangi field. This improved interpretation will further help reduce drilling risk, enhance the field's productivity and ultimately increase asset value.

\section{Acknowledgements}

The authorsspecially thank Shell Petroleum Development Company (SPDC) of Nigeria Limited, for permission to publish this work. We also express our heartfelt thanks to Dike S. Robinson, Francesca I. Osayande, PrahladBasak, Lucky M. Omudu and Temitope J. Jegede for their immense contributions. We appreciateall those who contributed by technical discussions and comments which have made this publication a success. Our kind regards also go to Anthony B. Chokor and his University Liaison team of the SPDC.

\section{References}

[1]. T. Mukerji, P. Avseth, G. Mavko, I. Takahashi, and E. F. González, Statistical rock physics: Combining rock physics, information theory, and geostatistics to reduce uncertainty in seismic reservoir characterization, The Leading Edge,20(3), 2001,313 - 319.

[2]. S. Samantaray, and P. Gupta, An interpretative approach for gas zone identification and lithology discrimination using derivatives of $\lambda *$ pand $\mu *$ pattributes, $7^{\text {th }}$ Biennial international Conference and Exposition on Petroleum Geophysics, "HYDERABAD 2008", Society of Petroleum Geophysicists, $386-341$.

[3]. B. Goodway, T. Chen, and J. Downton, Improved AVO fluid detection and lithology discrimination using Lame petrophysical parameters: " $\lambda \rho$ ", " $\mu \rho$ " and " $\lambda / \mu$ fluid stack", from P and S inversions, Canadian Society of Exploration Geophysicists Recorder, 1997, 3-5.

[4]. S. R. Rutherford, and R. H. Williams, Amplitude versus offset variations in gas sands. Geophysics, 54, $1989,680-688$.

[5]. J. P. Castagna, and S. W. Smith, Comparison of AVO indicators: A modeling study, Geophysics, 59(12), $1994,1849-1855$.

[6]. S. Chopra, V.Alexeev, and Y. Xu, 3D AVO crossplotting-An effective visualization technique, The Leading Edge, 22(11), 2003, $1078-1089$

[7]. R. Bachrach, M.Beller, C. C. Liu, J. Perdomo, D. Shelander, N. Dutta, and M. Benabentos, Combining rock physics analysis, full waveform prestack inversion and high resolution seismic interpretation to map lithology units in deep water: a Gulf of Mexico case study. The Leading Edge, 23(4), 2004, 378 - 383.

[8]. L. M. Omudu, J. O. Ebeniro,M. Xynogalas, N. Osayande,and S.Olotu, Fluid discrimination and reservoir characterization from onshore Niger Delta, Annual General Meeting, Las Vegas, Society of Exploration Geophysicists, 2008,2001 - 2005.

[9]. K. C. Short, and A. J. Stauble, Outline of geology of Niger Delta. TheAmerican Association of Petroleum Geologists Bulletin, 51(5), 1967, $761-799$.

[10]. [10]M. L. W. Tuttle, R. R. Charpentier, and M. E. Brownfield, The Niger Delta Petroleum System, Niger Delta Province, Nigeria, Cameroun and Equatorial Guinea, US Geological Survey, Denver, Colorado, United States of America, 1999, 6 - 29.

[11]. H. Doust, and E. Omatsola, Niger Delta, divergent/passive margin basins,American Association of Petroleum Geologists Memoir48, 1990, $239-248$.

[12]. S. Pochat, S. Castelltort, J. Van Den Driessche, K.Besnard, and C. Gumiaux, A simple method of determining sand/shale ratios from seismic analysis of growth faults: An example from upper Oligocene to lower Miocene Niger Delta deposits,TheAmerican Association of Petroleum Geologists Bulletin, 88(10), 2004, 1357 - 1367.

[13]. R. M. Bustin, Sedimentology and characteristics of dispersed organic matter in Tertiary Niger Delta: origin of source rocks in a deltaic environment,The American association of Petroleum Geologists Bulletin,72(3), 1988, 277 - 298.

[14]. J. I. Nwachukwu, and P. I. Chukwura, Organic matter of Agbada Formation, Niger Delta, Nigeria, The American Association of Petroleum Geologists Bulletin, 70(1), 1986, 48 - 55.

[15]. P. Stacher, Present understanding of the Niger Delta hydrocarbon habitat, (in Tuttle; Tertiary Niger Delta Petroleum System, Niger Delta Province), US Geological Survey Open file report, 1995,

[16]. Y. Li, L. Hunt and J. Downton, Sensitivity of rock properties in AVO analysis and prospect evaluation, Society of Exploration Geophysicists, Expanded Abstracts, 2000, 1 - 4.

[17]. J. P. Castagna, M. L. Batzle, and R. L. Eastwood,Relationships between compressional-wave and shear-wave velocities in elastic silicate rocks, Geophysics,50(4), 1985, 571-581.

[18]. J. L. Fatti, G. C. Smith,P. J. Vail,P. J. Strauss, and P. R. Levitt, Detection of gas in sandstone reservoirs using AVO analysis: A 3D seismic case history using the geostack technique. Geophysics, 59(9),1994, 1362 - 1376.

[19]. J. E. Calderon, and J. Castagna,Porosity and lithologic estimation using rock physics and multi-attribute transforms in Balcon Field, Colombia,The Leading Edge,26(2), 2007, 142 - 150.

[20]. Z. Wang, Fundamentals of seismic Rock Physics, Y2K Tutorial,Geophysics, Vol. 66(2), 2001, $398-412$.

[21]. A. Stovas, M. Landrø, and P. Avseth, AVO attribute inversion for finely layered reservoirs, Geophysics,71(3),2006, C25 - C36

[22]. G. B. Madiba, and G. A. McMechan, Processing, inversion, and interpretation of a 2D seismic data set from the North Viking Graben, North Sea,Geophysics, 68(3), 2003, 837 - 848 .

[23]. J. W. Ostrander, Plane wave reflection coefficients for gas sands at non-normal angles of incidence,Geophysics,49, 1984, 1637 1648 .

[24]. S. N. Domenico, Effect of brine gas mixture on velocity in an unconsolidated sand reservoir, Geophysics, 41(5), 1976, 882 - 894

[25]. G. C. Smith, andP. M. Gidlow, Weighted stacking for rock property estimation and detection of gas: Geophysical Prospectus, 35, 1987, 993-1014.

[26]. Veeken, and R. M. Davies, AVO attribute analysis and seismic reservoir characterization, First Break, 24,2006, 41 - 52.

[27]. R. Roden, M. Forrest, and R. Holeywell, The impact of seismic amplitudes on prospect risk analysis, The Leading Edge, 24(7), 2005, $706-801$.

[28]. J. Pendrel, and P. van Riel,Estimation and interpretation of $\mathrm{P}$ and S impedance volumes from simultaneous inversion of P-wave offset seismic data, Society of Exploration Geophysicists, Expanded Abstracts, 2000, 1 - 4.

[29]. P. Avseth, A. J. Wijngaarden, G. Mavko, andT. J. Johansen,Combined porosity, saturation and net-to-gross estimation from rock physics templates: Annual Meeting, New Orleans, Society of Exploration Geophysicists, 2006, 1856 - 1860.

[30]. P.Avseth, A. Jorstad, V. Aart-Jan, and G. Mavko, Rock physics estimation of cement volume, sorting, and net-to-gross in North Sea sandstones, The Leading Edge, 28(1), 2009, 98 - 108.

[31]. H. Feng, B. H. Russell, and J. C. Bancroft, A comparison of hydrocarbon indicators derived from AVO analysis, Consortium for Research in Elastic Wave Exploration Seismology Research Report,19, 2007, 1 - 9 